\title{
Feasibility and evaluation of Talk Boost KS2: A school- based programme for oral language skills in children with low-average communication skills in Key Stage 2.
} DOI:

$10.1177 / 0265659019874851$

\section{Document Version \\ Accepted author manuscript}

Link to publication record in Manchester Research Explorer

Citation for published version (APA):

Louisa, R., Freed, J., Hartshorne, M., \& Adams, C. (2019). Feasibility and evaluation of Talk Boost KS2: A schoolbased programme for oral language skills in children with low-average communication skills in Key Stage 2. Child Language Teaching and Therapy, 35(3), 221-240. [https://doi.org/10.1177/0265659019874851.].

https://doi.org/10.1177/0265659019874851

\section{Published in:}

Child Language Teaching and Therapy

\section{Citing this paper}

Please note that where the full-text provided on Manchester Research Explorer is the Author Accepted Manuscript or Proof version this may differ from the final Published version. If citing, it is advised that you check and use the publisher's definitive version.

\section{General rights}

Copyright and moral rights for the publications made accessible in the Research Explorer are retained by the authors and/or other copyright owners and it is a condition of accessing publications that users recognise and abide by the legal requirements associated with these rights.

\section{Takedown policy}

If you believe that this document breaches copyright please refer to the University of Manchester's Takedown Procedures [http://man.ac.uk/04Y6Bo] or contact uml.scholarlycommunications@manchester.ac.uk providing relevant details, so we can investigate your claim.

\section{OPEN ACCESS}




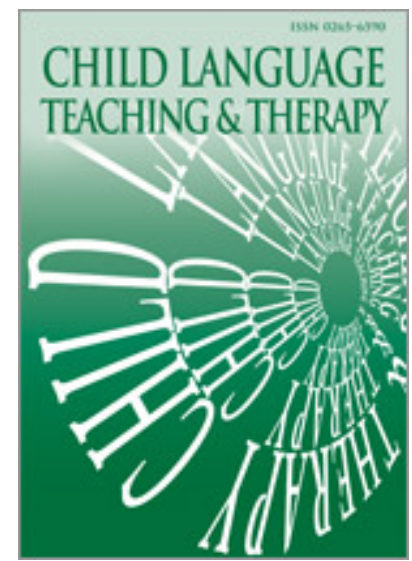

\section{Feasibility and evaluation of Talk Boost KS2: a school-based programme for oral language skills in children with low- average communication skills in Key Stage 2}

\begin{tabular}{|c|l|}
\hline Journal: & Child Language Teaching and Therapy \\
\hline Manuscript ID & CLT-18-0042.R2 \\
\hline Manuscript Type: & Original Manuscript \\
\hline Keywords: & $\begin{array}{l}\text { Targeted intervention, Key Stage 2, Language intervention, School based } \\
\text { intervention, oral language skills }\end{array}$ \\
\hline $\begin{array}{l}\text { Oral language skills in childhood are known to predict literacy levels and } \\
\text { academic performance. Identification of children's low-average oral } \\
\text { language skills in school is challenging when clear criteria for } \\
\text { developmental language disorder are not met. There are few studies of } \\
\text { targeted, school based oral language interventions for the older child. } \\
\text { This study aimed to investigate the feasibility of implementing and } \\
\text { evaluating a manualised language intervention (Talk Boost KS2) for } \\
\text { children aged between 7 and 9 years who were identified as having low- } \\
\text { average oral language skills, as delivered by trained teaching assistants } \\
\text { in mainstream schools. } \\
\text { Twenty-one UK mainstream primary schools each selected eight Year } 3 \\
\text { (7-8 year olds) and Year 4 (8-9 year olds) children with low-average oral } \\
\text { language skills. School staff received training in a new manualised } \\
\text { intervention, Talk Boost KS2. Schools were allocated to an Active } \\
\text { Intervention (AI) or a Waiting Control condition (WC) condition. The final } \\
\text { sample consisted of 162 children of which 87 were allocated to the AI } \\
\text { condition and 75 to the WC condition. Progress in favour of the } \\
\text { intervention was found on teacher ratings of speech, language and } \\
\text { communication needs and on a Learning Behaviours Checklist but not on } \\
\text { standardised language or reading comprehension tests. Parents of AI } \\
\text { children reported improvements in communication and language skills. } \\
\text { Teaching staff reported significant increases in confidence and } \\
\text { knowledge in managing children with low-average oral language skills as } \\
\text { a result of being involved in the intervention. The findings are discussed } \\
\text { in relation to the imperative to provide practical language intervention } \\
\text { tools as well training and support for education staff in order to support } \\
\text { children with low-average oral language skills in mainstream schools. }\end{array}$ \\
\hline
\end{tabular}


1

2

3

4

5

6

7

8

9

10

11

12

13

14

15

16

17

18

19

20

21

22

23

24

25

26

27

28

29

30

31

32

33

34

35

36

38

39

40

41

42

43

44

45

46

47

48

49

50

57

58

59

60

\section{SCHOLARONE ${ }^{\text {m }}$ \\ Manuscripts}

http://mc.manuscriptcentral.com/cltt 


\begin{abstract}
Oral language skills in childhood are known to predict literacy levels and academic performance. Identification of children's low-average oral language skills in school is challenging when clear criteria for developmental language disorder are not met. There are few studies of targeted, school based oral language interventions for the older child. This study aimed to investigate the feasibility of implementing and evaluating a manualised language intervention (Talk Boost KS2) for children aged between 7 and 9 years who were identified as having low-average oral language skills, as delivered by trained teaching assistants in mainstream schools.

Twenty-one UK mainstream primary schools each selected eight Year 3 (7-8 year olds) and Year 4 (8-9 year olds) children with low-average oral language skills. School staff received training in a new manualised intervention, Talk Boost KS2. Schools were allocated to an Active Intervention (AI) or a Waiting Control condition (WC) condition. The final sample consisted of 162 children of which 87 were allocated to the AI condition and 75 to the WC condition. Progress in favour of the intervention was found on teacher ratings of speech, language and communication needs and on a Learning Behaviours Checklist but not on standardised language or reading comprehension tests. Parents of AI children reported improvements in communication and language skills. Teaching staff reported significant increases in confidence and knowledge in managing children with low-average oral language skills as a result of being involved in the intervention. The findings are discussed in relation to the imperative to provide practical language intervention tools as well training and support for education staff in order to support children with low-average oral language skills in mainstream schools.
\end{abstract}

\title{
Declaration of Interest
}

Talk Boost KS2 was developed by specialist teachers and speech and language therapists working for I CAN, the children's communication charity. 
Evaluation of Talk Boost 2

\section{Introduction and purpose}

Studies have shown that children who enter school with low-average oral language skills are at a disadvantage in learning to read (Snowling \& Hulme, 2011) and in later academic achievement (Snowling et al, 2001), achieve fewer qualifications at the end of secondary schooling (Department for Education 2016, 2017). As well as this, limited language skills have been linked to behavioural, social and mental health problems (Yew and O’Kearney, 2013).

Identifying children at risk of adverse literacy, academic, communication and social outcomes begins with detection of low-average oral language skills at the pre-school stage. The majority of children who are 'late talkers' develop appropriate language skills (Bishop et al 2012), but a proportion retain significantly weaker language skills throughout development (Ellis and Thal, 2008). Within this article, the term "lowaverage oral language" is used to describe a group of children whose language difficulties may be transient, are unlikely to be classified as language disorder or to meet the criterion for specialist speech and language therapy services, but who are still likely to struggle at school. In the UK, children's needs are most frequently identified by schoolteachers, but after the first year of formal schooling routine assessment or monitoring of spoken language is not mandatory. Teachers report limited confidence in identifying oral language needs (The Communication Trust, 2017) and require support and suitable instruments to do this (Antonazzi, Snow \& Dickson-Smith, 2010).

There is a risk that, combined with increasing limitations on speech and language therapy (SLT) resources, many children's language difficulties are under-identified in schools in the UK. Research has shown that two-thirds of children with language difficulties were not referred to SLT clinical services, even when they do meet criteria for intervention (Law, Reilly and Snow, 2013). This situation is especially acute in areas of social disadvantage where $40-50 \%$ of children have been found to have a moderate- 


\section{Evaluation of Talk Boost 2}

severe language delay in their first term at nursery school (Locke, Ginsborg \& Peers, 2002; Law, McBean \& Rush, 2011).

Given the evident links between poor oral language and outcomes for non-clinical populations, there has been a steady development of a range of school-based interventions and evaluations targeted at this group. Bowyer-Crane et al (2008) compared the efficacy of a phonology/reading intervention to an oral language intervention for 152 children with weak oral language scores. Assignment to condition was randomised and group mean age at the start of the study was 4.8 years. Oral language intervention, delivered by trained teaching assistants, comprised a programme of instruction in narrative, comprehension, inference making and vocabulary. The phonology/reading condition contained phonological awareness training. After 20 weeks of intervention and at five month follow up, the oral language group made more progress than the phonology/reading group on measures of grammar and vocabulary, but the oral language condition did not demonstrate an effect on narrative and listening comprehension. The phonology/reading group conversely made more progress on phonological awareness measures that the oral language group but improvements in reading comprehension were not evident in either group.

Using a modified version of the Bowyer-Crane et al intervention, Fricke et al (2013) delivered an oral language intervention (Nuffield Early Language Intervention) over a 30 week period to 180 nursery school age children, identified as having low scores on formal language tests. Intervention, delivered again by trained teaching assistants, consisted of activities on narrative, vocabulary and active listening. Children in the control group were assigned to a waiting condition. Fricke et al found that children in the oral language intervention group showed greater improvement in oral language and narrative than the waiting control group, immediately after intervention and on reassessment six months later. Moreover there were indications that a generalisation effect of the oral language intervention on reading comprehension at six months 
Evaluation of Talk Boost 2

reassessment. Although, outcomes were primarily focused on reading skills, Fricke et al conclude that oral language intervention had contributed to educational improvements in at risk children.

The Talk of the Town project used a whole school approach to language development and employed a speech and language therapist to train and support teaching staff. The aim of this study was to improve workforce development of teaching staff in order to promote the development of age appropriate language skills in all children. Some targeted interventions were also included. The evaluation of the Talk of the Town project (Thurston et al 2016) did not find any evidence for improved oral language skills or reading comprehension but school staff valued the resources and training provided.

Studies have also focused on stimulation of children's language development in geographical areas where there is substantive social and economic deprivation. Davis, Shanks and Davis (2004) implemented a novel narrative intervention programme for 30 children (mean age 5;11 years) over one school term, three times as week. Children in six schools in areas of social disadvantage were identified by their teachers' judgements of weak oral language abilities but had not received any specific intervention. As with Bowyer-Crane et al and Fricke et al, the intervention was delivered in a group via a trained teaching assistant. Davis et al found significant improvements in sentence construction and narrative propositional content post intervention. This study was an exploratory study, without a control condition and children's communication needs were diverse. The outcomes, however, suggest that there may indeed be value in implementing a brief oral language focused intervention for vulnerable groups. In addition, Davis et al is unique in this field in also gathering functional perspectives from teaching staff who reported that children's classroom participation had improved postintervention. 


\section{Evaluation of Talk Boost 2}

Snow et al (2014) carried out a cluster-randomised trial of the effects of professional training of teachers to enhance oral children language skills. Fourteen schools from areas of social disadvantage in Australia were randomised to a research or control condition. In the research condition, teaching staff received intensive training in oral language facilitation; control school staff received training in curriculum guidelines. Snow et al found significant differences between research and control condition outcomes on measures of oral language ability and reading but not on narrative skills. These findings were welcomed as 'proof of concept' that focused teacher training could effect improvements in oral language skills in vulnerable populations.

Talk Boost interventions (ICAN ${ }^{1}$ ) have been evaluated in previous research. Lee and Pring (2015) report the effects of an intervention delivered by participating schools' teaching assistants after training in language-facilitating techniques. The programme, Talk Boost, targeted 180 children identified by their teachers as having immature language skills and was delivered in to small groups over 30 sessions. Eighteen schools, all from areas of social disadvantage, were assigned randomly to either Talk Boost treatment or control. Children from treatment schools improved significantly more on measures of sentence production and story telling than control schools, but children who received treatment remained delayed in terms of language skills.

In other Talk Boost research, Reeves et al (2018) investigated Early Talk Boost, a pre-school version of the programme, and its effect on language development in three year olds attending nurseries. Research was carried out in an area of social disadvantage as in the Davies et al and Lee and Pring's studies. Nursery staff were trained in Early Talk Boost and children were assessed prior to and three months after the completion of the intervention. Children who received intervention made significantly greater gains in language growth (4.93 months) compared to a waiting control group (2.33 months).

\footnotetext{
${ }^{1}$ Details of ICAN programmes can be obtained at https://icancharity.org.uk/talk-boost-ks1homepage
} 
Evaluation of Talk Boost 2

In conclusion, there is now a substantial research literature that provides evidence of preferred outcomes for children with low-average oral language skills both in typical mainstream primary schools and in nursery provision when teacher-led interventions are provided. There is emerging evidence that these approaches are associated with improvements in children's language skills in areas of social deprivation. Further advantages of these approaches is that teachers, teaching assistants and nursery staff can be appropriately trained to deliver a language intervention and that the intervention can be delivered within the context of a school or nursery over a brief period of time. There may also be benefits from manualisation of the intervention such that training is supported with documentation and that consistency of the approach is achieved.

Studies have, however, tended to focus rightly on pre-school and school entry provision, where language facilitation methods are well developed. There are few studies of targeted, school based oral language interventions for the older child with low-average oral language skills. This study aims to address this imbalance by providing exploratory data on implementation of a teacher-delivered intervention for older children in primary schools in England.

The term Key Stage 2 refers to a part of the compulsory national curriculum for 7-11 year olds in England (https://www.gov.uk/national-curriculum). The curriculum covers a range of subjects with mandatory testing at age 11 years. During Key Stage 2 (KS2) there are increased demands on oral language, combined with fewer visual prompts, requirements for more advanced executive functioning in the organisation of written work and learning/thinking in more abstract language. These requirements present increased challenges to children who have low-average communication skills (Matson \& Cline, 2012).

The current study involved delivery of a new intervention, Talk Boost KS2, for children at Key Stage 2. This extends the theme of school-based training outlined above, whilst introducing an intervention aimed at some of the key features of the Key Stage 2 
Evaluation of Talk Boost 2

curriculum. The intervention was designed to address the needs of the group of children identified by teachers as needing support for their language and communication skills but who do not meet the threshold for specialist assessment or intervention. This feasibility study is necessarily exploratory in nature as the first step in investigating a signal of change and appropriate endpoints for a full trial. The specific aims were to investigate the effectiveness of Talk Boost Key Stage 2 intervention; to ascertain if there are there improvements in communication and language skills associated with the intervention, compared to a waiting control condition; and to investigate acceptability and feasibility of the intervention in the school context.

The specific research questions addressed were:

1. In a sample of children with teacher-identified weak oral language skills at Key Stage 2, are there improvements in communication and language skills following a short oral language intervention (Talk Boost 2) delivered by trained teaching assistants compared to a waiting control condition?

2. Are changes in communication and language evident on standardised tests of oral language, reading comprehension, teacher evaluation of communication skills/classroom listening behaviours or parent ratings of communication changes?

3. Is the intervention acceptable and feasible to implement in a UK mainstream primary school?

\section{Method}

\section{Ethical permissions}

Ethical approval for the study was obtained from the I CAN Research Ethics Committee. Written informed consent was obtained from parents and from young people.

\section{Study design and timeline}


Evaluation of Talk Boost 2

The study design was a small-scale exploratory crossover trial, with random assignment at the level of school, to an Active Intervention (AI) group (who received Talk Boost KS2 intervention) or a Waiting Control (WC) condition. All participants completed baseline measures at Time 1. Children in the AI group then received 8 weeks of intervention, three times a week. Outcome measures were then taken at Time 2, one school term (12 weeks) after the Time 1 measures. After the Time 2 measures had been completed the WC group received the Talk Boost KS2 intervention.

\section{Participants and recruitment}

Twenty-one primary mainstream schools were recruited via Local Authority and SLT services in Kirkby, York, Leeds and Somerset. Each school was asked to select eight children in total (four from year 3 (age 7 or 8 years) and four from year 4 (age 8 or 9 years). Children with additional special educational needs (SEN) who had been identified by the school but who did not have a formal diagnosis were included. Information was gathered on participants' eligibility for free school meals (FSM) as a proxy for social deprivation eligibility. Children with English as Additional Language (EAL) were eligible to participate in the study. The final sample, consisting of 162 participants in 21 schools, was allocated randomly at the level of school ${ }^{2} .11$ schools (87 children) were allocated to $\mathrm{AI}$ and 10 schools (75 children) to WC.

Child participants were selected for inclusion using a two-stage process.

Stage 1 inclusion: General guidelines for selection were written by the first author and were provided to the school's nominated study organiser (typically the Special Educational Needs Coordinator (SENCO) or other senior school staff member. These guidelines asked the school staff to identify children with any observed difficulties in listening or paying attention, vocabulary development or understanding language.

\footnotetext{
${ }^{2}$ Group allocation at the school level entailed unequal groups at the start of the study. Not all schools were able to provide eight children and one school only ran one group of four; this school was randomly assigned to the Waiting Control group during the allocation process.
} 
Evaluation of Talk Boost 2

Identification guidelines also listed the presence of immature sentence forms, difficulties explaining or describing events, information and instructions; and difficulties socialising/interacting with peers as inclusion characteristics. Participants with known conditions were excluded from this study: developmental speech and/or language disorders with existing specialist support; Specific language impairment; Autistic Spectrum Disorder; Long term significant cognitive and learning difficulties.

Stage 2 inclusion: Selection was confirmed by teacher completion of the Speech, Language and Communication Progression Tools (SLCPT) (The Communication Trust n.d.) for each participant. The SLCPT is a set of non-standardised developmental communication descriptors of five main subscales of language development: Understanding spoken language; Understanding and Using Vocabulary; Sentence Production; Story Telling and Narrative; Speech and Social Interaction. Each subscale is rated separately out of a maximum of 15 . Scores are assigned a rating of Red, Amber or Green. Subscale ratings falling in the Green range (scores 15-13) are considered typical for the child's age; scores in Amber range (12-5) indicate some cause for concern; and scores falling in the Red range (below 5 ) indicate the child may need specialist investigation and support. At the point of inclusion, all SLCPT subscale scores for all participants fell within the Amber category with group scores ranging from 8.26 to 10.91. Characteristics of school-selected participants are shown in Table 1.

Table 1 about here

\section{Intervention Procedure}

After the recruitment period, teacher and teaching assistant (TA) pairs from one Year 3 and one Year 4 class in each AI school attended a one-day training course on Talk Boost KS2 methods and the manual/resources required to run the intervention. Training was provided by the first author (an ICAN senior practitioner and speech and language therapist) and other ICAN intervention staff. WC schools received training and materials for the intervention in the same manner after Time 2 only. No other ongoing 
Evaluation of Talk Boost 2

coaching or any input from other agencies such as speech and language therapy (other than for excluded children with known special educational needs) was provided during the period of the intervention.

AI schools carried out Talk Boost 2 KS2 over a period of eight weeks, with three sessions per week, each lasting approximately forty minutes. Intervention sessions were delivered by the schools' trained teachers and TAs to groups of four children. Each school ran a Year 3 and a Year 4 Talk Boost KS2 group separately. Whole class activities, suggested in the manual, were linked to the small group work of AI groups and guidance on extension activities was included to ensure newly learned skills were thoroughly embedded.

\section{Intervention content}

The content of the manual was organised into five main components with a focus on both receptive and expressive language skills: active listening, vocabulary, narrative skills, making friends, conversation skills and problem solving. A teacher manual and an intervention manual were developed along with a Communication Detective Notebook for the children to use to support their learning during the intervention. Manualised teaching materials were organised into a set of sessions with clear learning objectives that were shared with the children; the aim was to enable children to know what is expected and when they have achieved it (Sutton Trust, 2011).

The intervention was predicated on 10 key treatment principles relevant to child language learning in the Key Stage 2 age range:

1) Evidence-informed - approaches and strategies included in the intervention are based on either direct research evidence or specialist experience;

2) Visual support: Visual resources provided in the manual support the spoken message and reinforce the child's learning; 
Evaluation of Talk Boost 2

3) Repetition - activities, key words and sentences are repeated to help children become more secure in their knowledge and understanding.

4) Clear learning objectives - each session has clearly outlined objectives which are shared with the children so they know what is expected and when they have achieved it;

5) Explicit feedback - giving children clear feedback linked specifically linked to learning objectives is one of the most effective methods for raising attainment;

6) Meta-linguistic skills - talking about language and communication and encouraging children to use language to talk about language helps them become aware of the skills they need;

7) Clear demonstration and practice of social rules during sessions - positive reinforcement of appropriate social communication skills is an explicit component of the intervention;

8) Recording progress - methods and training to take baseline and repeated measures are included in the intervention so that school staff measure the progress of individual children;

9) Differentiation - guidance on adapting the activities to meet the needs of individual children is included and this is specifically addressed in the training so that scaffolding of children's learning takes place.

10) Consolidation/embedding skills - whole class activities are linked to the small group work and guidance on extension activities are included to ensure newly learned skills are thoroughly embedded and active learning takes place.

The intervention was designed by a specialist teacher and speech and language therapist with experience of supporting children with speech and language needs in schools across the UK. Components were selected as known areas of difficulty for children with low-average oral language skills and as increasingly important aspects of 
Evaluation of Talk Boost 2

the curriculum in KS2. A number of key theoretical and practical influences guided the development of the manual. For example, comprehension monitoring activities (Dollaghan \& Kaston, 1986), vocabulary instruction techniques (Beck, McKeown \& Kucan, 2013; Steele \& Mills, 2011; St John \& Vance. 2014); and advisory guidelines for the inclusion of teaching assistants in group instruction/principles of group work (Kershner et al, 2014).

The manual provided some guidance on adapting or differentiating the activities to meet the needs of individual children, but the emphasis was on small group work. Whole class activities, suggested in the manual, were a central component to help embed and generalise skills from the small group environment of the intervention to the whole class environment. A sample session plan from the Talk Boost 2 KS2 Intervention manual is shown in Appendix 1.

\section{Baseline and outcome measures}

All formal language and reading assessments, at all time points and for both groups, were completed by evaluation assistants (EAs). EAs were all student speech and language therapists from universities in the north west of England in their second or third year of training. They were recruited directly via university-ICAN links and received pre-study training on the evaluation process and baseline/outcome measures and were blind to school condition and assessment time point. Teachers, TAs and parents could not be blind to group allocation as informed consent and training was associated with condition.

The following measures were administered at Time 1 (baseline) and Time 2 (after intervention, 12 weeks later).

Participant measures:

- Four subtests of the Assessment of Comprehension and Expression (ACE) 6-11

(Adams et al, 2001) - Sentence Comprehension; Semantic Decisions; Naming and Narrative Propositions. 
Evaluation of Talk Boost 2

- The York Assessment of Reading for Comprehension (Snowling et al, 2009): Reading Accuracy and Reading Comprehension subtests.

Teacher-completed measures

The participant's class teacher completed the SLCPT for each child at Time 1 and Time 2. A Learning Behaviour Checklist (LBC) (see Appendix 2) was completed by the teacher or TA at Time 1 and 2. The LBC is based on developmental norms for the typical communication behaviours that support learning in the classroom. Teachers rate children's classroom communication behaviours by their perceived frequency of occurrence on a scale from 1 (never seen) to 5 (all of the time) according the frequency of occurrence of the behaviour.

Teacher outcome measure

All school staff (class teachers and TAs) in both AI and WC conditions completed a Staff Outcomes Questionnaire (SOQ) at Time 1 and Time 2. Participants rated their confidence in identifying and supporting children with low-average oral language skills on a scale of 1 to 5 , where $1=$ not at all confident and $5=$ very confident.

Parent-reported measure

Parents of children who had received intervention (i.e., AI participants and WC participants after delayed intervention) were invited to complete a Parent Rating Scale (PRS) at Time 2 in the form of a questionnaire. Parents reported their perception of change on a simple categorical scale (better/the same/worse) in child functional communication skills. Selected communication skills in the PRS were: 1) Listens when people talk to him/her; 2) Understands when you talk to him/her; 3) Says when s/he doesn't understand you; 4) Asks about unfamiliar words; 5) Happy to talk to family members; 6) Plays with other children and can take turns; 7) Talks about what he/she is interested in; 8) Talks about what they did at school; 9) Shares a book with you or someone they are close to and talks about it. 
Evaluation of Talk Boost 2

\section{Teaching staff evaluation and reflection on acceptability}

Teaching staff were asked to evaluate Talk Boost KS2 training immediately after their training was completed using a standard evaluation questionnaire. In addition, five school staff members from different settings completed semi-structured interviews after Time 2 reflecting on the implementation of Talk Boost KS2 in the school environment. Interviews were carried out by a member of ICAN staff not involved in the development or implementation of the project. The five staff members were two SENCOs, one inclusion manager, one assistant head and one teaching assistant.

\section{Results}

\section{Plan of analysis}

Group characteristics will be analysed using the chi-squared statistic for comparison of categorical data to explore if there are any differences between the $\mathrm{AI}$ and WC groups on age, gender, SEN, free school meal eligibility or number of children with English as an additional language. Baseline scores on the ACE and YARC will be compared between groups to see if the proportion of children scoring in the impaired and non impaired range is similar for the $\mathrm{AI}$ and $\mathrm{WC}$ groups.

Child participant outcomes will be analysed by comparing change scores between Time 1 and Time 2 (Time 2-Time1) between the AI and WC groups. Prior to analysis, Shapiro Wilks tests will be used to check whether the data is normally distributed. Analysis for the main outcome Speech, Language and Communication Progression Tool and ACE will use a Mann Whitney U test as the data is not normally distributed. Analysis for the YARC will use independent samples t-tests as this data is normally distributed. The analysis for the total LBC score will use an independent samples t-test. Post-hoc Mann Whitney U tests will be used to compare change scores for each of the LBC items as the data at the item level is not normally distributed. Parent and teacher outcomes are explored by description only.

\section{Missing data}


Evaluation of Talk Boost 2

One child participant declined to consent after enrolment but before group allocation and was withdrawn from any further involvement. Between Time 1 and Time 2, $10 \mathrm{AI}$ participants and $17 \mathrm{WC}$ participants were lost to follow-up due to lack of attendance in school intervention sessions or failure to attend Time 2 assessments.

\section{Child participant baseline scores and group characteristics}

Comparison of group characteristics shown in Table 1 indicated that there was no difference between $\mathrm{AI}$ and WC group on age $(t=0.953, \mathrm{p}>0.05), \operatorname{SEN}\left(\chi^{2}=0.10, p>0.05\right)$, gender $\left(\chi^{2}=2.203, p>0.05\right)$ or free school meal eligibility $\left(\chi^{2}=3.423, p>0.05\right)$. There was a between groups difference with the WC group containing significantly fewer children with English as Additional Language than the $\mathrm{AI}$ group $\left(\chi^{2}=6.775, p<0.05\right)$.

Table 2 shows the proportions of participants falling into impaired and nonimpaired on ACE and YARC at Time 1. Groups AI and WC are comparable across ACE Sentence Comprehension, Naming and Semantic Decisions, with approximately half of each group falling into the normal range and half falling into the impaired range (except ACE Narrative Propositions). On YARC, the majority of children in both conditions scored in the normal range.

Table 2 about here

\section{Child participant outcomes}

Time 1 - Time 2 Speech, Language and Communication Progression Tool

Table 3 about here

Table 3 shows the mean scores for children in the AI and WC groups Time 1 and Time 2 on the SLCPT subscales. There was a significant difference between the two groups on change scores for five out of the six subscales (Understanding Spoken Language (Mann Whitney $U=1567.50, p=0.002$ ), Understanding and Using Vocabulary $(U=1492.00, p=0.001)$, Sentence Production $(U=1437.50, p<0.001)$, Story Telling and Narrative $(U=1419.00, p<0.001)$ and Speech $(U=715.50, p=0.002))$. In the AI group, 
Evaluation of Talk Boost 2

each of these subscales scores increased significantly more between Time 1 and Time 2 than scores for the WC group. There was no between groups difference on change scores for the Social Interaction subscale $(U=2055.50, p=0.475)$.

Time 1 - Time 2 Language and reading comprehension tests

Table 4 about here

Table 4 shows the mean standard scores for children in the AI and WC groups at Time 1 and Time 2 on ACE and YARC subtests. For all ACE subscales, there was no significant difference between the change scores for the AI and WC groups (Sentence Comprehension (Mann Whitney $U=2519.00, p=0.862$ ), Naming ( $U=2526.00, p=0.753$ ), Semantic Decisions $(U=2295.00, p=0.279)$ Narrative Propositions $(U=2229.00$, $p=0.424)$ ). Separate independent samples t-tests on YARC subtests showed no significant difference between change scores for the AI and WC groups (accuracy $(t(127)=-1.424, p=0.157)$, comprehension $(t(128)=-0.702, p=0.484)$.

Time 1 - Time 2 Learning Behaviour Checklist

Table 5 shows the mean ratings on each of the items on the LBC at Time 1 and Time 2 for the AI (available data $\mathrm{N}=67$ ) and WC (available data $\mathrm{N}=36$ ) groups.

Table 5 about here

Ratings on each of the 11 items were totalled to provide an overall score for the Learning Behaviour Checklist. An independent samples t-test of LBC total scores showed a significant difference between the two groups $(t(101)=-4.981, p<0.001)$ with AI group scores increasing significantly more than WC between Time 1 and Time 2 . Post-hoc comparisons of changes in each LBC item are shown in Table 5. There were significant differences for eight out of the 11 LBC items between Time 1 and Time 2 with AI showing larger gains in LBC scores compared to WC.

\section{Teacher outcome measure}


Evaluation of Talk Boost 2

SOQ data was available from 49 participants $(\mathrm{AI}(\mathrm{N}=23)$ and $\mathrm{WC}(\mathrm{N}=26))$.

Confidence in identification of and support for language skills increased in both groups post intervention, with a higher increase in the AI group. The average change in rating for AI staff was 0.4 for identifying children and 0.7 for supporting language. In WC schools the differences were 0.2 for identifying children and 0.2 for supporting language.

\section{Parent-reported outcome measure}

Figure 1 about here

Thirty-nine PRS questionnaires were completed (out of a total N of 162 children), a return rate of $24 \%$. Given the relatively small numbers, a descriptive analysis of the data only was attempted. A summary of results from the returned questionnaires (AI group only) is shown in Figure 1. No parents selected the 'changes for the worse' category for any question in any group. The largest reported improvements were shown on items: Your child's overall communication, Says when he doesn't understand, Asks about unfamiliar words, Happy to talk to family members, Talks about things they are interested in. There was little difference between groups on reported changes in Listens when people talk, Talks about school and Shares a book.

\section{Acceptability of Talk Boost KS intervention}

The final aim of this study was to elicit information about the acceptability of the intervention and training from teaching staff. This was done via teaching staff questionnaire and via structured interviews with a sample of senior school teaching staff involved in the intervention.

Questionnaire: Eighty-eight staff members completed training evaluations. Ninetytwo percent of respondents stated the training would influence the way they worked and $98 \%$ would recommend the training to others. The aspects of the training which were perceived as the most useful aspect was the opportunity to explore the resources, to learn about the programme and ask questions about its delivery was most useful. 
Evaluation of Talk Boost 2

Staff Interviews: Interviews were audio recorded, transcribed and thematically analysed using Braun and Clarke’s model (Braun \& Clarke, 2006) - reading/re-reading transcriptions, developing a coding framework and grouping the codes into themes. Themes were then discussed with the rest of the project team to ensure they were representative of the data. Two key themes identified were a) the impact of Talk Boost KS2 on children and b) the impact on staff. School staff stated that they could clearly identify the impact of the programme on the children who had participated. Staff commented that children had enjoyed taking part in Talk Boost KS2. They also perceived that children were more confident speaking out loud and their ability to listen, to follow instructions, the accuracy of their speech and their sentence structure had all improved.

"All the pupils now, are much better at listening and not just looking like they're listening but actually engaging and thinking about the same thing and about questions they want to ask. That's been quite a big change in all of the children" (Assistant Head).

School staff described the pride children taking part in Talk Boost KS2 had in sharing their learning with their peers and how they would remind peers about 'good sitting' and 'good listening'. For school staff, participating in Talk Boost KS2 raised their awareness of the issue of speech and language needs and increased understanding of the links between reading/writing and a communication difficulty. Staff also felt it had improved their ability to identify those children who had difficulties in communicating but who did not meet criteria for developmental language disorder:

"It's teasing out those that are easy to spot with very significant needs........and it's about that next bracket down because it looks very different between Key Stage 1 and Key Stage 2 that can look very different so no yeah it's made life easier" (Inclusion manager).

\section{Discussion}


Evaluation of Talk Boost 2

The main finding of this study is that, after a short period of teacher-delivered Talk Boost KS2 intervention, children in the active intervention group showed an increase in Speech, Language and Communication Progression Tool subscales scores compared to a waiting control group. An advantage of intervention over WC was observed for SLCPT subscales Use and Understanding of Spoken Language and Understanding Vocabulary, Speech, Producing Sentences and Storytelling/narrative. Ratings for the Social Interaction subscale improved slightly in both groups but there was no effect of intervention. These findings are in line with other evaluations of targeted oral language interventions (e.g., Bowyer-Crane et al 2008, Fricke et al, 2013). They also reflect the findings of other studies that have employed Talk Boost interventions (Lee \& Pring, 2016; Reeves et al, 2018). Caution in interpretation of these outcomes is required, since judgements of these communication skills were made by teachers who were also involved in the intervention training and in delivery and who were not blind to the group status of the participants.

Using formal measures and blind assessors, there was no significant difference between groups (Active Intervention vs. Waiting Controls) on Time 1 to Time 2 formal language test scores (ACE subtests of Sentence Comprehension, Naming, Semantic Decisions and Narrative Propositions). On each ACE subtest there was an increase in ability over time for both groups. The results for the YARC Accuracy subtest showed no between group Time 1 to Time 2 differences in reading accuracy scores. On the YARC Reading Comprehension subtest, children's comprehension ability in both conditions decreased slightly between Time 1 and Time 2, which might be a result of increasing demands of the comprehension task as age increases. There was no difference between groups in terms of the magnitude of this change. Our findings are not unexpected as there have been mixed effects in terms of establishing that reading outcomes can be affected by oral language interventions. Like Bowyer-Crane et al (2008) and Thurston et al (2016) we were unable to find any effect on formal assessment of reading 
Evaluation of Talk Boost 2

comprehension. It may be that additional components of intervention are required to see positive outcomes in reading skills (as in Fricke et al (2013)) and future studies may wish to analyse more fully the separate components of intervention included in the treatment protocol.

Teacher or teaching-assistant ratings on the Learning Behaviour Checklist at Time 2 were significantly higher for the AI group compared to the WC group. The majority of items on this Checklist were rated as having improved at Time 2 in the AI group, including ratings of "Shows appropriate listening skills most of the time", "Shares ideas on stories/discussion", "Joins in group activities" and "Says when does not understand". Some differentiation in the judgements was shown across items, suggesting that teachers were not simply applying a blanket 'improved' judgement across all communication skills. As with the SLCPT findings, items that related directly to the intervention were rated as improved, such as those closely connected to vocabulary use. Our findings on teacher-reported behaviour are similar to the improved functional ratings of communication skills associated with intervention obtained in Davis et al's study (2004). It may be wise to include functional perspectives of teaching staff in further larger-scale research. Teacher rating is the most commonly used method of measuring educational progress in the UK, so use of scales such as the SLCPT fit well with the paradigm of measurement of skills in these settings. However, despite their functional value, there are outstanding problems of validity and reliability with these ratings that remain unexplored.

The second implication for measurement is that standardised language tests present problems of sensitivity in capturing communication needs and changes in language ability within a 'sub-clinical' population. In this study, teachers' ratings of communication skills across the different subscales of SLCPT identified a group of children whose language skills were of concern to teachers in learning situations, but who had not been recognised as having language impairment. Findings from a reading 


\section{Evaluation of Talk Boost 2}

assessment (YARC) identified only a small proportion of these children as having reading skills outside the normal range. A standardised language test (ACE) identified more children as falling outside the normal range (between $38-52 \%$ depending on ACE subtest), although most scores approached the normal range cut-off. The SLCPT may have a valuable role in providing descriptors of the language and communication skills expected at different age groups in non-clinical terms that are accessible to teaching staff. Since it is accepted that teachers are not receiving sufficient training or information to match the needs of children with SLCN (Antoniazzi et al 2010) better identification via a functional rating tool such as SLCPT, supplemented by objective assessment should be promoted as good practice. The development of further criterionreferenced assessments or validation of extended functional instruments may be necessary to supplement language testing. This is essential if requirements of internal validity for evidence generation with this population are to be met.

Parents who returned the Parent Rating Scale post intervention, were very likely to report improvements across most items. More than sixty percent of ratings indicated improved communication skills, however it is likely that parents who had more engagement with the intervention or who were able to see observable changes in their children were more likely to return the questionnaire. There was some indication that parents tended to rate items not related to the intervention as having stayed the same. This analysis is exploratory only, given the non-blinded status of participating parents. It may be the case that some parents value a chance to become involved with similar targeted programmes of intervention, either because they perceive a chance to assist their children following advice from school or because they are made aware for the first time that their child may be falling behind in oral language skills. Further exploration of parents' views and understanding of the intervention and their children's' communication skills is ongoing. 
Evaluation of Talk Boost 2

The outcomes of this feasibility study are limited by a number of factors, especially by the lack of blinding of SLCPT evaluators. This measure was included as a school-friendly scale that teachers and assistants could relate to language work in the classroom and which could reflect the functional communication performance of the child in school. In order to use the SPCLT in future larger scale research, some work would be necessary to establish the validity of the SPCLT as an accurate measure of functional communication skills against a recognised measure of these skills. Further limitations include the absence of sufficient data to analyse the contribution of EAL status or FSM eligibility within the study. A larger sample was required to provide sufficient power to carry out moderator analysis on this data.

The absence of control follow-up was a consequence of the necessity of crossing over from WC to active intervention at Time 2 as stipulated by the ICAN ethics committee and agreed with schools. In future research, it would be necessary to provide more distance between intervention and control groups within a time period and to measure carefully the fidelity of the intervention. However, it is important to note that the crossover method was the preferred one for schools and met with the desire to ensure fairness across all pupils. In the current study, no measures of attendance at the pupil level or treatment fidelity measures of delivery of the manualised intervention were made. These would be essential in future research in order to establish that the intervention in terms of content and method was delivered as planned, and to estimate the amount of intervention delivered for each child or group was as planned.

A central aim of this project was to identify the challenges of conducting research in a mainstream school context and to evaluate an intervention that could be delivered in a practical and flexible manner after a short period of training by teachers and teaching assistants in a mainstream school. In general, school staff viewed the intervention and training very positively, with reported increased confidence in targeted staff in the use of strategies to support the language and communication skills 


\section{Evaluation of Talk Boost 2}

of children aged 7-10 years in mainstream primary school. In a follow-up study of school staff who participated in this study, $92 \%$ of teaching staff reported that the Talk Boost KS2 training would substantially change the way in which they approached working with children with language and communication needs. Staff who participated in the programme felt more confident identifying children with SLCN and supporting their language than those who did not.

This research supports the recent review of evidence of effectiveness supporting the view that teacher-led interventions be appropriate for children with Tier 2 language status (defined as children with language weaknesses or vulnerabilities) (Ebbels et al 2018). In general our findings were modest and this may reflect the brevity and/or the limited impact of the intervention. Two questions arise from this model of teacher-led delivery: firstly, are teachers being asked to evaluate themselves? In future research, it would be essential to have observations of SLCPT skills by teaching staff who know the children but who are not invested in the intervention delivery.

Secondly, it is important to carry out further research into the longevity of the intervention and to the range of outcomes achieved. Ebbels et al (2018) found that outcomes of teacher-led interventions were generally better when ongoing monitoring and coaching were provided and were of the opinion that more intense training was important for long-lasting change at the level of the school. We only provided training before the intervention. In future research, additional attention should be paid to the manner in which support is provided across the period of intervention and whether this is provided by a speech and language therapist and/or specialist education staff. In addition, findings from two key studies have provided clear indications that intervention delivered as a group, single procedure manualised treatment may be of limited value for some participants. For example, Thurston et al (2016) found that not all participants were sufficiently challenged by the treatment protocol employed. The implications of this are significant, since they argue for differentiation of group 
Evaluation of Talk Boost 2

interventions according to need and this may, in turn, argue that a multi-track treatment is required.

\section{Conclusions and future research}

The contribution of this project to the growing body of evidence about oral language interventions for 7-9 year old children who have weak but not clinically impaired language skills is to show that a brief, targeted manualised language intervention can be delivered by teachers and teaching assistants after a short period of training. There are indications of positive effects of the intervention on functional measures of communication skills and ratings of learning behaviours. Such an intervention can be beneficial for children at Key Stage 2 whose communication needs are revealed as the oral language demands of the curriculum increase. Snow and Powell (2008) have suggested that such interventions have a strong preventative role against later academic and behavioural failures, to the extent that they should become part of a 'strategic public health intervention'. This may be especially acute in areas of social deprivation where many children enter school with unidentified SLCN needs that are likely to impact on academic progress. Evidence is increasing that speech and language therapists have a valuable public health role in training schools to deliver practicable interventions for these children both at school entry and at Key Stage 2 level. Further larger scale studies, embedded within the school-context, which deliver appropriately validated evidence are required. The intervention was deliverable in the context of a mainstream school environment and manualisation has made replicability and scalability a realistic proposition for teaching staff with no specialist knowledge or expertise with speech and language needs.

\section{References}

Adams, C., Cooke, R., Crutchley, A., Hesketh, A. and Reeves D., 2001, ACE (6-11): Assessment of Comprehension and Expression (6-11). Windsor: NFER-Nelson. 
Evaluation of Talk Boost 2

Antoniazzi, D, Snow, P and Dickson-Swift, V. (2010). Teacher identification of children at risk for oral language impairment in the first year of school, International Journal of Speech- Language Pathology, 12, pp. 244-252.

Beck, I. L., McKeown, M. G., \& Kucan, L. (2013). Bringing words to life: Robust vocabulary instruction. Guilford Press.

Bishop, D. V., Holt, G., Line, E., Mcdonald, D., Mcdonald, S., and Watt, H. (2012). Parental phonological memory contributes to prediction of outcome of late talkers from 20 months to 4 years: a longitudinal study of precursors of specific language impairment. Journal of Neurodevelopmental Disorders, 4(3) Bowyer-Crane, C., Snowling, M. J., Duff, F. J., Fieldsend, E., Carroll, J. M., Miles, J., Gotz, K., and Hulme, C. (2008). Improving early language and literacy skills: Differential effects of an oral language versus a phonology with reading intervention. Journal of Child Psychology and Psychiatry, 49(4), pp.422-432.

Braun, V. and Clarke, V. (2006). Using Thematic Analysis in Psychology, Qualitative Research in Psychology, 3 (2), pp.71-101.

The Communication Trust (nd.) Speech, Language and Communication Progression Tools - Primary

https://www.thecommunicationtrust.org.uk/resources/resources/resources-forpractitioners/progression-tools-primary. Accessed June 2018

Davies, P., Shanks, B., and Davies, K. (2004). Improving narrative skills in young children with delayed language development. Educational Review, 56(3), pp.271-286.

Ebbels, S. H., McCartney, E., Slonims, V., Dockrell, J. E., \& Norbury, C. F. (2019).

Evidence-based pathways to intervention for children with language

disorders. International journal of language \& communication disorders, 54(1), 3-19.

Department for Education (2016) National curriculum assessments: key stage 2, 2016 (revised)

Dollaghan, C., \& Kaston, N. (1986). A comprehension monitoring program for languageimpaired children. Journal of Speech and Hearing Disorders, 51(3), 264-271. 
Evaluation of Talk Boost 2

Ellis, E.M. and Thal, D.J. (2008). Early Language Delay and risk for language impairment. Perspectives on Language Learning and Education, 15, pp.93-100.

Fricke, S., Bowyer-Crane, C., Haley, A., Hulme, C. and Snowling, M. (2013). Efficacy of language intervention in the early years. Journal of Child Psychology and Psychiatry, 54(3), pp.280-290.

Kershner, R., Warwick, P., Mercer, N., \& Kleine Staarman, J. (2014). Primary children's management of themselves and others in collaborative group work:'Sometimes it takes patience...'. Education 3-13, 42(2), 201-216.

Law, R., McBean, K. and Rush, R., (2011). Communication skills in a population of primary school-aged children raised in an area of pronounced social disadvantage. International Journal of Language and Communication Disorders, 46 (6), pp. 657-664. Law, J., Reilly, S. and Snow, P.C. (2013). Child speech, language and communication need re-examined in a public health context: a new direction for the speech and language profession International Journal of Language and Communication Disorders, 48 (5), pp. 486-496.

Lee, W., \& Pring, T. (2016). Supporting language in schools: Evaluating an intervention for children with delayed language in the early school years. Child Language Teaching and Therapy, 32(2), 135-146

Locke, A., Ginsborg, J. and Peers, I. (2002). Development and disadvantage: implications for the early years and beyond. International Journal of Language and Communication Disorders, 37(1), pp.3-15.

Matson, G. and Cline, T. (2012). The impact of specific language impairment on performance in science and suggested implications for pedagogy. Child Language Teaching and Therapy, 28(1), pp. 25-37.

Reeves, L., Hartshorne, M., Black, R., Atkinson, J., Baxter, A., \& Pring, T. (2018). Early talk boost: A targeted intervention for three year old children with delayed language development. Child Language Teaching and Therapy, 34(1), 53-62. 
Evaluation of Talk Boost 2

Snowling, M.J., Adams, J.W., Bishop, D.V.M. and Stothard, S.E. (2001). Educational attainments of school leavers with a preschool history of speech-language impairments. International Journal of Language \& Communication Disorders, 36(2), pp. 173-183.

Snowling, M. J., and Hulme, C. (2011) Evidence-based interventions for reading and language difficulties: Creating a virtuous circle. British Journal of Educational Psychology, 81(1), pp. 1-23.

Snowling, M. J., Stothard, S. E., Clarke, P., Bowyer-Crane, C., Harrington, A., Truelove, E., Nation, K. and Hulme, C (2009) York Assessment of Reading for Comprehension Passage Reading. London: GL Assessment.

St. John, P. and Vance, M. (2014) Evaluation of a principled approach to vocabulary learning in mainstream classes Child Language Teaching and Therapy, vol. 30 no. 3255271)

Steele, S. C., \& Mills, M. T. (2011). Vocabulary intervention for school-age children with language impairment: A review of evidence and good practice. Child Language Teaching and Therapy, 27(3), 354-370.

Sutton Trust (2011). Improving the impact of teachers on pupil achievement in the UK interim findings. http://www.suttontrust.com/wp-

content/uploads/2011/09/2teachers-impact-report-final.pdf (accessed May 2017).

Thurston, A., Roseth, C., O'HARE, L., Davison, J., \& Stark, P. (2016). Talk of the

Town. Evaluation report and executive summary. Education Endowment Foundation.

Yew, S. G. K., and O'Kearney, R. (2013). Emotional and behavioural outcomes later in childhood and adolescence for children with specific language impairments: meta-analyses of controlled prospective studies. Journal of Child Psychology and Psychiatry, 54(5), pp. 516-524.

\section{Acknowledgements:}


Evaluation of Talk Boost 2

The authors would like to thank all the children, parents and schools who took part in the study and also the Evaluation Assistants who helped us to gather the information.

This project was supported by grants from Alasol Charitable Foundation, Eleanor

Rathbone Charitable Trust and Sir Jules Thorn Charitable Trust. 
Evaluation of Talk Boost 2

\section{Appendix 1}

Sample of Talk Boost KS2 intervention plan

Week 4:/Telling Stories and saying what happens/Summary

Week 4: Session 1

SUMMARY

\begin{tabular}{|l|l|l|l|}
\hline Activity & Time & $\begin{array}{l}\text { Learning Objective } \\
\text { Activity description }\end{array}$ & Resources provided \\
\hline Activity 1 & 5 Minutes & $\begin{array}{l}\text { Tell a story with a beginning, } \\
\text { middle and end, containing key } \\
\text { story components } \\
\text { Review the Homework activity for } \\
\text { Week 3: Storytelling homework }\end{array}$ & $\begin{array}{l}87^{*} \text { Storytelling } \\
\text { homework }\end{array}$ \\
\hline Activity 1 & 5 minutes & $\begin{array}{l}\text { Know how to tell a good story } \\
\text { Communication Detective } \\
\text { Notebook: Activity 3: What do I } \\
\text { know about stories }\end{array}$ & $\begin{array}{l}\text { Communication } \\
\text { Detective Notebook }\end{array}$ \\
\hline Activity 1 & 10 minutes & $\begin{array}{l}\text { Tell a group story using the key } \\
\text { story components } \\
\text { Invent a new story and each child } \\
\text { contributes one of the components: } \\
\text { Who? When? Where? What } \\
\text { happens? How does it end? }\end{array}$ & $\begin{array}{l}\text { 33 Story content } \\
\text { cards (from Week 3: } \\
\text { Session 3) }\end{array}$ \\
\hline Activity 1 & 5 minutes & $\begin{array}{l}\text { Use conjunctions when telling a } 1 \\
\text { story } \\
\text { Practise joining sentences from the } \\
\text { story: Activity 3) using conjunctions }\end{array}$ & $\begin{array}{l}\text { 36 Conjunction } \\
\text { word cards }\end{array}$ \\
\hline Review & 5 minutes & $\begin{array}{l}\text { Can you remember the different } \\
\text { parts of the story? } \\
\text { Complete the Session review chart }\end{array}$ & $\begin{array}{l}\text { 1 Session review } \\
\text { chart }\end{array}$ \\
\hline
\end{tabular}

* refer to the resource number in the Talk Boost KS2 manual 
2

Evaluation of Talk Boost 2

\section{Appendix 2}

\section{Learning Behaviour Checklist}

The checklist should be completed by the class teacher or a teaching assistant who knows how the child is in class. Use rating scales from 1= never; 2 = rarely, even when supported; 3 = sometimes; 4 = frequently; 5 = all of the time (please refer to the Speech, Language and Communication Progression Tool for indication of age appropriate skills)

\begin{tabular}{|c|c|c|}
\hline Skill & Rating & Comments \\
\hline $\begin{array}{l}\text { Shows appropriate listening skills (sitting still, } \\
\text { looking at the speaker, thinking about the same } \\
\text { thing) most of the time, with very few reminders }\end{array}$ & & \\
\hline $\begin{array}{l}\text { Makes simple relevant, related comments to class } \\
\text { discussions }\end{array}$ & & \\
\hline Shares ideas on stories / discussions & & \\
\hline $\begin{array}{l}\text { Uses communication skills to make friends \& } \\
\text { negotiate in activities }\end{array}$ & & \\
\hline $\begin{array}{l}\text { Says when s/he doesn't understand, giving some } \\
\text { indication of exactly what s/he hasn't understood }\end{array}$ & & \\
\hline $\begin{array}{l}\text { Knows what resources are needed for most class- } \\
\text { based tasks and is able to organise herself/himself } \\
\text { to complete tasks independently }\end{array}$ & & \\
\hline Joins in group activities & & \\
\hline $\begin{array}{l}\text { Talks in small groups to peers: } \\
\text { Makes helpful contributions, attempting different } \\
\text { roles (e.g. questioner / chairperson / note-taker) } \\
\text { when speaking in turn, in pairs and in small groups }\end{array}$ & & \\
\hline $\begin{array}{l}\text { Talks in class to adults: } \\
\text { Answers direct questions; responds to ideas with } \\
\text { generally relevant comments and suggestions } \\
\text { through sustained speaking turns }\end{array}$ & & \\
\hline $\begin{array}{l}\text { Uses age appropriate vocabulary when talking: } \\
\text { Varies vocabulary choice according to audience and } \\
\text { topic }\end{array}$ & & \\
\hline $\begin{array}{l}\text { Uses narrative skills when telling a story: } \\
\text { Includes clear structure \& relevant detail; connects } \\
\text { ideas \& makes meaning clear in most situations }\end{array}$ & & \\
\hline
\end{tabular}


Evaluation of Talk Boost 2

Table 1: Characteristics of participants by group at Time 1.

\begin{tabular}{|l|l|l|}
\hline & Active Intervention & Waiting Control \\
\hline $\mathrm{N}$ & 87 & 75 \\
\hline Ages (mean/sd) & 8 years 2 months (SD 0.81) & 8 yrs. 1 month (SD 0.77) \\
\hline$\%$ EAL & $18 \%(\mathrm{n}=16)$ & $5 \%(\mathrm{n}=3)$ \\
\hline$\%$ FSM & $51 \%(\mathrm{n}=42)$ & $37 \%(\mathrm{n}=27)$ \\
\hline$\%$ girls & $36 \%(\mathrm{n}=31)$ & $27 \%(\mathrm{n}=20)$ \\
\hline $\begin{array}{l}\text { \% Year } 3 \\
(\text { ages } 7-8)\end{array}$ & $49 \%(\mathrm{n}=43)$ & $53 \%(\mathrm{n}=40)$ \\
\hline $\begin{array}{l}\text { \% Year 4 } \\
(\text { ages 9-10) }\end{array}$ & $51 \%(\mathrm{n}=44)$ & $47 \%(\mathrm{n}=35)$ \\
\hline \begin{tabular}{l} 
\% SEN \\
\hline
\end{tabular} & $46 \%(\mathrm{n}=39)$ & \\
\hline
\end{tabular}

Key: EAL= English as an Additional Language; FSM= eligible for Free School Meals; SEN+ Special Educational Need identified by school 
Evaluation of Talk Boost 2

Table 2: Proportions of participants falling into impaired and non-impaired range on ACE and YARC at Time 1

\begin{tabular}{|c|c|c|c|c|}
\hline & \multicolumn{2}{|c|}{ Active Intervention group (AI) } & \multicolumn{2}{|c|}{ Waiting Control group (WC) } \\
\hline & $\begin{array}{l}\text { Children with } \\
\text { scores in } \\
\text { normal range }\end{array}$ & $\begin{array}{l}\text { Children with } \\
\text { scores below } \\
\text { normal range }\end{array}$ & $\begin{array}{l}\text { Children with } \\
\text { scores in } \\
\text { normal range }\end{array}$ & $\begin{array}{l}\text { Children with } \\
\text { scores below } \\
\text { normal range }\end{array}$ \\
\hline $\begin{array}{l}\text { ACE Sentence } \\
\text { Comprehension }\end{array}$ & $\begin{array}{l}N=46 \\
53 \%\end{array}$ & $\begin{array}{l}\mathrm{N}=41 \\
47 \%\end{array}$ & $\begin{array}{l}N=35 \\
56 \%\end{array}$ & $\begin{array}{l}\mathrm{N}=28 \\
44 \%\end{array}$ \\
\hline ACE Naming & $\begin{array}{l}\mathrm{N}=42 \\
48 \%\end{array}$ & $\begin{array}{l}\mathrm{N}=45 \\
52 \%\end{array}$ & $\begin{array}{l}\mathrm{N}=33 \\
52 \%\end{array}$ & $\begin{array}{l}\mathrm{N}=30 \\
48 \%\end{array}$ \\
\hline $\begin{array}{l}\text { ACE Semantic } \\
\text { Decisions }\end{array}$ & $\begin{array}{l}N=47 \\
54 \%\end{array}$ & $\begin{array}{l}\mathrm{N}=40 \\
46 \%\end{array}$ & $\begin{array}{l}\mathrm{N}=35 \\
56 \%\end{array}$ & $\begin{array}{l}\mathrm{N}=28 \\
44 \%\end{array}$ \\
\hline $\begin{array}{l}\text { ACE Narrative } \\
\text { Propositions }\end{array}$ & $\begin{array}{l}N=53 \\
62 \%\end{array}$ & $\begin{array}{l}\mathrm{N}=33 \\
38 \%\end{array}$ & $\begin{array}{l}\mathrm{N}=30 \\
49 \%\end{array}$ & $\begin{array}{l}\mathrm{N}=31 \\
51 \%\end{array}$ \\
\hline YARC Accuracy & $\begin{array}{l}\mathrm{N}=66 \\
81.5 \%\end{array}$ & $\begin{array}{l}\mathrm{N}=15 \\
18.5 \% \%\end{array}$ & $\begin{array}{l}\mathrm{N}=50 \\
88 \%\end{array}$ & $\begin{array}{l}\mathrm{N}=7 \\
12 \%\end{array}$ \\
\hline $\begin{array}{l}\text { YARC } \\
\text { Comprehension }\end{array}$ & $\begin{array}{l}\mathrm{N}=67 \\
85 \%\end{array}$ & $\begin{array}{l}\mathrm{N}=12 \\
15 \%\end{array}$ & $\begin{array}{l}\mathrm{N}=53 \\
91 \%\end{array}$ & $\begin{array}{l}\mathrm{N}=5 \\
9 \%\end{array}$ \\
\hline
\end{tabular}

Key: ACE = Assessment of Comprehension and Expression (6-11), below normal range is a score of less than 7 which is 1 SD below mean; YARC = York Assessment of Reading Comprehension, below normal range is a score of less than 85 which is $1 \mathrm{SD}$ below mean 
Evaluation of Talk Boost 2

Table 3: Mean scores (standard deviation) for children in the Active Intervention and Waiting Control at Time 1 and Time 2 on the Speech, Language and Communication Progression Tool (SLCPT)

\begin{tabular}{|l|c|c|c|c|}
\hline \multirow{2}{*}{ SLCPT subscale } & \multicolumn{2}{|c|}{ Waiting Control } & \multicolumn{2}{c|}{ Active Intervention } \\
\cline { 2 - 5 } & Time 1 & Time 2 & Time 1 & Time 2 \\
\hline $\begin{array}{l}\text { Understanding } \\
\text { Spoken Language * }\end{array}$ & $10.38(2.35)$ & $10.41(2.65)$ & $11.57(2.43)$ & $13.08(1.79)$ \\
\hline $\begin{array}{l}\text { Understanding and } \\
\text { Using Vocabulary* }\end{array}$ & $9.76(2.43)$ & $10.52(2.96)$ & $10.59(2.86)$ & $12.71(2.59)$ \\
\hline $\begin{array}{l}\text { Sentence Production * } \\
\text { Story Telling } \\
\text { and Narrative* }\end{array}$ & $9.88(3.36)$ & $10.48(3.10)$ & $10.27(2.88)$ & $12.55(2.68)$ \\
\hline $\begin{array}{l}\text { Speech* } \\
\text { Social Interaction }\end{array}$ & $9.26(2.68)$ & $8.45(2.64)$ & $8.79(2.71)$ & $11.09(2.73)$ \\
\hline * & $10.10(2.25)$ & $10.91(2.61)$ & $10.87(2.17)$ & $11.95(2.03)$ \\
\hline
\end{tabular}

* indicates a significant difference between AI and WC conditions at Time 2 on this subscale.

Notes:

a) Each subscale is scored out of 15 , with higher scores indicating a higher level of ability

b) $\mathrm{N}$ for subscales Understanding and Using Vocabulary and Social Interaction: $\mathrm{n}=58 \mathrm{WC}, 76 \mathrm{AI}$, for Speech: n=37 WC, $61 \mathrm{AI}$. 
Evaluation of Talk Boost 2

Table 4: Mean standard scores (standard deviations) for children in the WC and AI groups at Time 1 and Time 2 on the ACE and YARC.

\begin{tabular}{|l|l|l|l|l|}
\hline & \multicolumn{2}{|l|}{ Waiting Control } & \multicolumn{2}{l|}{ Active Intervention } \\
\cline { 2 - 5 } & Time 1 & Time 2 & Time 1 & Time 2 \\
\hline $\begin{array}{c}\text { ACE Sentence } \\
\text { Comprehension }\end{array}$ & $7.28(2.68)$ & $8.85(3.00)$ & $7.01(2.86)$ & $8.44(3.19)$ \\
\hline ACE Naming & $6.94(2.44)$ & $8.16(2.59)$ & $6.62(2.58)$ & $7.71(2.85)$ \\
\hline $\begin{array}{c}\text { ACE Semantic } \\
\text { Decisions }\end{array}$ & $7.05(3.02)$ & $8.08(2.46)$ & $6.85(2.69)$ & $7.54(2.33)$ \\
\hline $\begin{array}{c}\text { ACE Narrative } \\
\text { Propositions }\end{array}$ & $6.86(2.79)$ & $8.97(2.68)$ & $7.32(2.67)$ & $8.93(2.77)$ \\
\hline YARC Accuracy & $98.77(11.85)$ & $96.76(11.67)$ & $93.61(10.22)$ & $93.33(10.38)$ \\
\hline $\begin{array}{c}\text { YARC } \\
\text { Comprehension }\end{array}$ & $96.07(10.06)$ & $91.80(8.94)$ & $93.58(10.25)$ & $90.55(10.55)$ \\
\hline
\end{tabular}

Note: ACE standard scores are based on a population mean of 10 and standard deviation of 3;

YARC Standard scores are based on a population mean of 100 and standard deviation of 15

Standard scores $<70$ on the YARC have been recoded as 69 for the purposes of the analysis.

Due to time limitations and performance variables, not all data were available on every

subtest. Data is available for the following numbers of participants in each subtest: ACE

Sentence Comprehension and Semantic Decisions n=61 WC, 84 AI; Naming n=62 WC, 84 AI;

Narrative Propositions n=59 WC, 82 AI, YARC accuracy n=53 WC, 76 AI and YARC

comprehension $\mathrm{n}=54 \mathrm{WC}, 76 \mathrm{AI}$. 
Evaluation of Talk Boost 2

Table 5: Mean (standard deviation) Learning Behaviour Checklist scores at Time 1 and

Time 2 by group

\begin{tabular}{|c|c|c|c|c|c|c|}
\hline & \multicolumn{2}{|c|}{ Waiting Control } & \multicolumn{2}{|c|}{$\begin{array}{l}\text { Active } \\
\text { Intervention }\end{array}$} & \multicolumn{2}{|c|}{$\begin{array}{c}\text { Results from post- } \\
\text { hoc Mann } \\
\text { Whitney U test }\end{array}$} \\
\hline & Time 1 & Time 2 & Time 1 & Time 2 & $U$ & $p$ \\
\hline $\begin{array}{l}\text { Shows appropriate } \\
\text { listening skills most of } \\
\text { the time }\end{array}$ & $\begin{array}{l}3.29 \\
(0.80)\end{array}$ & $\begin{array}{l}3.28 \\
(0.81)\end{array}$ & $\begin{array}{l}3.13 \\
(0.90)\end{array}$ & $\begin{array}{l}3.81 \\
(0.82)\end{array}$ & 644.00 & $<0.001$ \\
\hline $\begin{array}{l}\text { Makes relevant } \\
\text { comments to class } \\
\text { discussions }\end{array}$ & $\begin{array}{l}2.64 \\
(0.76) \\
\end{array}$ & $\begin{array}{l}2.87 \\
(0.73)\end{array}$ & $\begin{array}{l}2.87 \\
(0.81)\end{array}$ & $\begin{array}{l}3.42 \\
(0.82)\end{array}$ & 983.50 & 0.102 \\
\hline $\begin{array}{l}\text { Shares ideas on } \\
\text { stories/discussions }\end{array}$ & $\begin{array}{l}2.58 \\
(0.87)\end{array}$ & $\begin{array}{l}2.81 \\
(0.71)\end{array}$ & $\begin{array}{l}2.81 \\
(0.82)\end{array}$ & $\begin{array}{l}3.46 \\
(0.66)\end{array}$ & 858.50 & 0.010 \\
\hline $\begin{array}{l}\text { Uses communication } \\
\text { skills to make friends }\end{array}$ & $\begin{array}{l}2.90 \\
(0.86)\end{array}$ & $\begin{array}{l}3.25 \\
(0.91)\end{array}$ & $\begin{array}{l}3.09 \\
(0.90)\end{array}$ & $\begin{array}{l}3.75 \\
(0.80)\end{array}$ & 984.50 & 0.101 \\
\hline $\begin{array}{l}\text { Says when doesn't } \\
\text { understand }\end{array}$ & $\begin{array}{l}2.39 \\
(0.69)\end{array}$ & $\begin{array}{l}2.67 \\
(0.72)\end{array}$ & $\begin{array}{l}2.48 \\
(0.84)\end{array}$ & $\begin{array}{l}3.30 \\
(0.89)\end{array}$ & 750.50 & 0.001 \\
\hline $\begin{array}{l}\text { Knows what } \\
\text { resources are needed, } \\
\text { organises self }\end{array}$ & $\begin{array}{l}2.81 \\
(0.98)\end{array}$ & $\begin{array}{l}3.19 \\
(0.98)\end{array}$ & $\begin{array}{l}2.87 \\
(0.90)\end{array}$ & $\begin{array}{l}3.42 \\
(0.91)\end{array}$ & 1022.50 & .172 \\
\hline $\begin{array}{l}\text { Joins in group } \\
\text { activities }\end{array}$ & $\begin{array}{l}2.96 \\
(0.68)\end{array}$ & $\begin{array}{l}2.83 \\
(0.74)\end{array}$ & $\begin{array}{l}3.33 \\
(0.70)\end{array}$ & $\begin{array}{l}3.87 \\
(0.76)\end{array}$ & 671.50 & $<0.001$ \\
\hline $\begin{array}{l}\text { Talks in small groups } \\
\text { to peers }\end{array}$ & $\begin{array}{l}2.69 \\
(0.91)\end{array}$ & $\begin{array}{l}2.68 \\
(0.65)\end{array}$ & $\begin{array}{l}2.79 \\
(0.83)\end{array}$ & $\begin{array}{l}3.40 \\
(0.92)\end{array}$ & 733.00 & 0.001 \\
\hline Talks in class to adults & $\begin{array}{l}2.69 \\
(0.91) \\
\end{array}$ & $\begin{array}{l}2.97 \\
(0.74) \\
\end{array}$ & $\begin{array}{l}2.97 \\
(0.80) \\
\end{array}$ & $\begin{array}{l}3.58 \\
(0.82) \\
\end{array}$ & 956.00 & 0.069 \\
\hline $\begin{array}{l}\text { Uses age appropriate } \\
\text { vocabulary when } \\
\text { talking }\end{array}$ & $\begin{array}{l}2.58 \\
(0.84)\end{array}$ & $\begin{array}{l}2.74 \\
(0.71)\end{array}$ & $\begin{array}{l}2.72 \\
(0.70)\end{array}$ & $\begin{array}{l}3.36 \\
(0.77)\end{array}$ & 886.50 & 0.020 \\
\hline $\begin{array}{l}\text { Uses narrative skills } \\
\text { when telling a story }\end{array}$ & $\begin{array}{l}2.25 \\
(0.76)\end{array}$ & $\begin{array}{l}2.51 \\
(0.55)\end{array}$ & $\begin{array}{l}2.51 \\
(0.69)\end{array}$ & $\begin{array}{l}3.39 \\
(0.87)\end{array}$ & 744.00 & $<0.001$ \\
\hline Total score & $\begin{array}{l}29.79 \\
(5.82)\end{array}$ & $\begin{array}{l}31.81 \\
(5.10)\end{array}$ & $\begin{array}{l}31.57 \\
(5.90)\end{array}$ & $\begin{array}{l}38.75 \\
(6.35)\end{array}$ & & \\
\hline
\end{tabular}

Note. The final two columns show results from post-hoc Mann-Whitney $\mathrm{U}$ tests comparing change scores (Time 2 - Time 1) between the Waiting Control and Active Intervention groups. 
Evaluation of Talk Boost 2

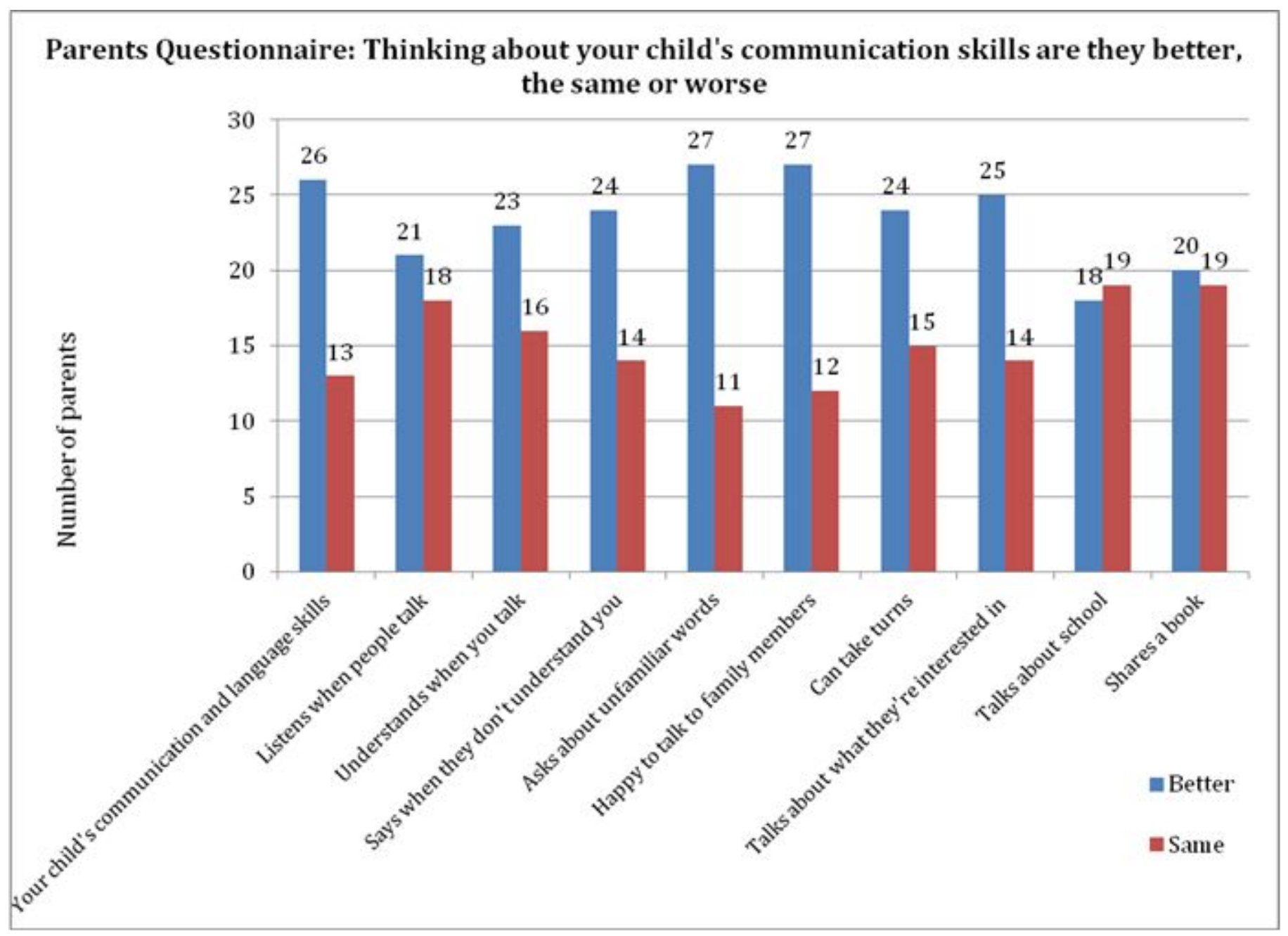

Figure 1: Parent Rating Scale outcomes post intervention for AI group only (N=39 returned) 